\title{
PENGARUH JUMLAH SUDU DAN KECEPATAN TERHADAP DAYA YANG DIHASILKAN GENERATOR LISTRIK DC SAAT BERKENDARA
}

\author{
Rudianto \\ Teknik Mesin, Fakultas Teknik \\ Universitas Maarif Hasyim Latif, Sidoarjo, Indonesia \\ e-mail : rudianto@student.umaha.ac.id
}

\begin{abstract}
ABSTRAK
Kebutuhan listrik yang sudah tersimpan pada media penyimpanan listrik (Power Bank) sangat diperlukan khususnya bagi orang saat bepergian atau orang yang profesinya yang selalu mobile ( berpindah - pindah tempat ) agar keperluan komunikasinya lancar. Dengan memasang sudu pada generator DC serta meletakkanya pada kendaraan, maka akan timbul arus DC sehingga proses pengisian listrik pada Power Bank bisa dilakukan saat berkendara.

Pengambilan data dibagi menjadi 3 percobaan, yaitu: Percobaan pertama untuk mengetahui variasi tegangan dan Kecepatan putaran generator. Percobaan kedua untuk mengetahui kestabilan Rangkaian pembatas tegangan sebesar 5 volt dan Percobaan ketiga untuk mengetahui besar Arus saat pengisian ke Power Bank.

Dari Variasi jumlah sudu dan Variasi kecepatan berkendara, didapatkan data yang menunjukkan Daya saat pengisian Arus ke Power Bank $2600 \mathrm{mAh}$ yang dihasilkan oleh sudu 4 terbesar dibandingkan dengan sudu 2, sudu 3, sudu 5 dan sudu 6. Jadi jumlah sudu paling efektif terhadap daya yang dihasilkan oleh Generator listrik DC saat berkendara adalah sudu 4 sebesar $844,44 \mathrm{~mW}$ pada kecepatan $70 \mathrm{~km} / \mathrm{jam}$.
\end{abstract}

Kata kunci: Daya, Generator Listrik DC, Kecepatan, Power Bank, Rangkaian pembatas tegangan, Sudu.

\section{PENDAHULUAN}

Saat berkendara kita memiliki kecepatan, sebagaimana Pembangkit Listrik bertenaga Angin yang memanfaatkan aliran kecepatan angin alami untuk menghasilkan suatu Energi listrik. Maka seharusnya dengan memanfaatkan aliran angin dari kecepatan berkendara kita juga bisa mendapatkan Energi listrik. Dengan memasang Generator DC mini pada kendaraan, yang dihubungkan sudu untuk memutar Generator tersebut maka akan timbul arus DC sehingga proses pengisian listrik pada Power Bank yang biasa kita lakukan dirumah bisa diganti dengan pengisian saat berkendara.

Untuk mengetahui besarnya Energi dan Daya listrik yang dihasilkan serta jumlah sudu yang efektif agar diperoleh Arus pengisian maksimal, maka penelitian ini kami lakukan. Penelitian ini akan mencari hubungan antara jumlah sudu dan kecepatan berkendara terhadap Tegangan dan rotasi permenit yang dihasilkan, serta pengaruh Rangkaian pembatas Tegangan (Dioda zener) terhadap variasi Tegangan masuk dan besar Arus pada saat pengisian ke Power Bank dengan prosentase kapasitas yang berbeda sehingga diketahui besarnya Daya maksimal pada masing-masing sudu.

\section{METODE PENELITIAN}

Perancangan (planning) penelitian. merupakan proses awal kegiatan untuk mendapatkan hasil yang diharapkan, setelah perancangan selesai maka pelaksanaan penelitian bisa dilakukan. Penelitian ini dimulai dari observasi langsung yaitu mengamati kebiasaan yang sering dilakukan oleh kalangan penggemar layang - layang yang memasang Generator Listrik DC (Dinamo DC) untuk menghasilkan Energi cahaya menggunakan diode LED yang dilakukan malam hari serta dengan mempelajari jurnal dan penelitian sebelumnya tentang pemanfaatan dinamo/ Generator DC untuk menghasilkan Energi listrik.

Data yang diperoleh merupakan hasil dari percobaan yang dilakukan 2 sampai 5 kali, setelah diperoleh data rata-rata pada tiap percobaan maka penyusunan laporan dilakukan. Adapun diagram alir penelitian ini pada gambar 2.1 sebagai berikut: 


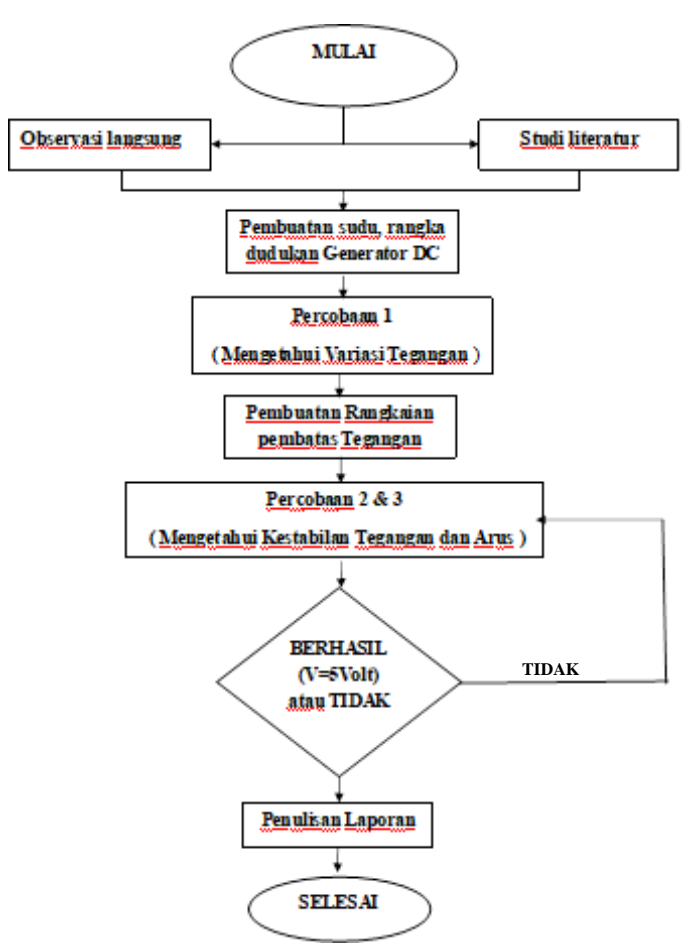

Gambar 2.1 Diagram alir penelitian

Bahan Dan Alat

Bahan :

a. Generator listrik DC

b. Baling - baling (Sudu 2,3,4,5 \& 6)

c. Rangka (dudukan) Generator DC.

d. Baut dan Mur

e. Dioda Zenner dan Resistor (Rangkaian pembatas Tegangan)

f. Kabel

Alat - Alat :

a. MultiMeter.

b. Tacho Meter

c. Power Bank (2600 mAh)

d. Obeng dan Tang

Tempat dan Waktu Penelitian

Penelitian dilakukan selama 2,5 bulan yang dimulai dari perencanaan alat dan percobaan dilaksanakan di Tol KLBM (pada saat masih belum digunakan).

\section{Langkah - langkah Penelitian}

Alur penelitian ini terbagi menjadi 3 percobaan, setelah pembuatan dudukan yang terpasang pada sepeda motor dan sudu sesuai desain maka dilakukan percobaan pertama yaitu untuk mengetahui variasi Tegangan dan Kecepatan rotasi per menit yang dihasilkan secara langsung tanpa Rangkaian pembatas Tegangan. Setelah diketahui Tegangan dan rpm maksimal, maka dilakukan percobaan yang kedua yaitu mengetahui tingkat kestabilan Tegangan yang dihasilkan setelah dipasang Rangkaian pembatas tegangan (Dioda zener 5,1volt) karena pengisian optimum Power bank saat tegangan yang bekerja sebesar 5 volt. Setelah Tegangan yang dihasilkan telah sesuai maka dilakukan percobaan ketiga yaitu mengetahui besarnya pengisian Arus pada Power bank, ada 5 macam perlakuan yaitu pada saat kapasitas Power Bank 100\% (penuh), 75\%, 50\%, 25\% dan 0\% (kosong). Dari 5 perlakuan ini didapat Arus rata-rata pada (tabel 3.4 dan 3.5)

Berikut ini adalah desain sederhana sudu yang dipakai pada penelitian ini, dengan 1 daun sudu membentuk sudut $60^{\circ}$ serta jari-jari dalam $15 \mathrm{~mm}$ dan jari-jari luar $55 \mathrm{~mm}$. Bahan terbuat dari seng 0,5 mm dan sudut kemiringan $20^{\circ}$ merupakan Turbin angin jenis Horzontal.
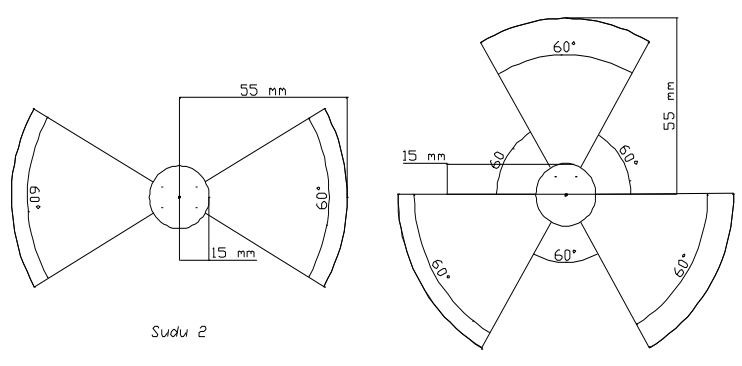

Sudu 3

Gambar 2.2 Desain sudu 2 dan sudu 3

Adapun Generator listrik yang dipakai di penelitian (Gambar 2.3) ini merupakan Dinamo DC bekas dipakai pada Bor Mini dengan tegangan input 12 sampai 24 volt, dan4000 rpm sampai dengan $7000 \mathrm{rpm}$ putaran tanpa beban. Diameter As 3,1mm, panjang As depan 8,28mm Panjang As total 52,0mm panjang casing 37,44mm diameter casing luar 29,8 dan diameter casing belakang $27,8 \mathrm{~mm}$.

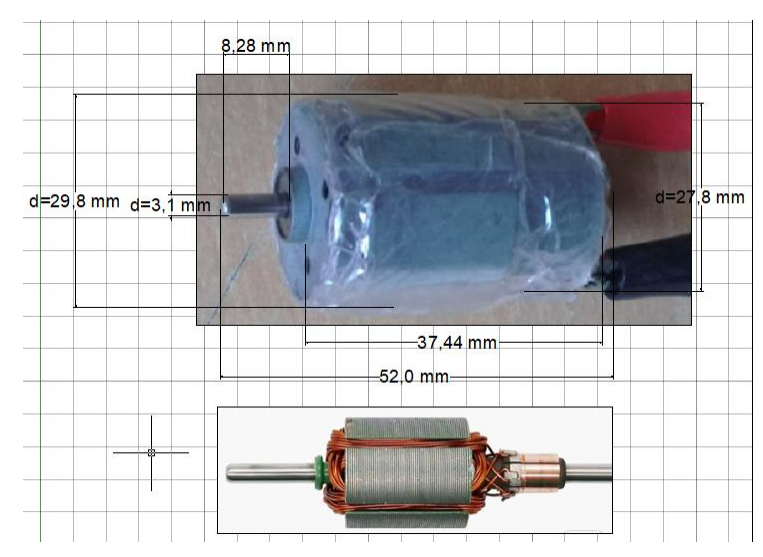

Gambar 2.3 Skema dan Foto Generator DC 


\subsection{Percobaan 1}

Percobaan ini dilakukan untuk bisa Mengetahui Variasi Tegangan dan rpm dengan kecepatan dan Jumlah Sudu yang bervariasi.

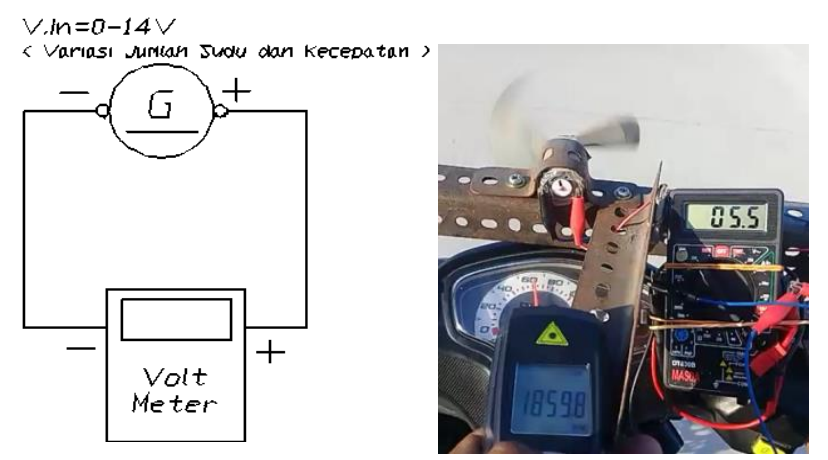

Gambar 2.4 Skema dan Foto percobaan 1

Setelah proses wiring selesai, Multimeter (+/-) dihubungkan ke Generator DC, setelah sudu dipasang dan proses berkendara dimulai Tachometer diukurkan pada As belakang. Nilai rpm yang keluar pada Tachometer dan tegangan pada Multimeter dicatat pada kecepatan $10 \mathrm{~km} / \mathrm{jam}$ sampai $70 \mathrm{~km} / \mathrm{jam}$. Data rata-rata hasil percobaan tercatat pada tabel 3.1 dan tabel 3.2.

\subsection{Percobaan 2}

Percobaan ini dilakukan untuk bisa mengetahui kestabilan Tegangan yang dihasilkan oleh Dioda zener (Rangkaian Pembatas Tegangan) sebesar 5,1 volt. Tegangan sebesar 5,1 volt dibutuhkan sebagai Tegangan input untuk pengisian ke Power Bank.

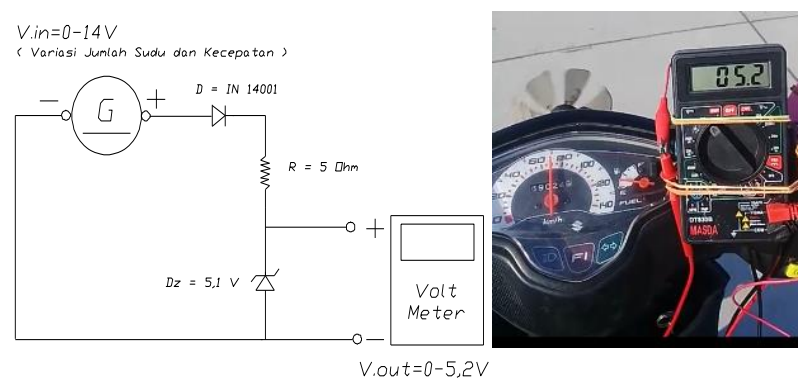

Gambar 2.5 Skema dan Foto percobaan 2

Setelah proses wiring selesai, Multimeter (+/-) dihubungkan ke Generator DC, setelah sudu dipasang dan proses berkendara dimulai Tegangan pada Multimeter dicatat pada kecepatan $10 \mathrm{~km} / \mathrm{jam}$ sampai $70 \mathrm{~km} / \mathrm{jam}$. Data rata-rata hasil percobaan tercatat pada tabel 3.3

\subsection{Percobaan 3}

Percobaan ini dilakukan untuk bisa mengetahui berapa besar Arus yang mengalir saat proses pengisian ke Power Bank 2600 mAh, sehingga diketahui besarnya Daya pengisian pada sisa kapasitas 0\%,25\%,50\%,75\% dan $100 \%$.

Setelah proses wiring selesai, Multimeter (+/-) dihubungkan secara seri rangkaian pembatas tegangan dan Power Bank, setelah sudu dipasang dan proses berkendara dimulai Arus pada Multimeter dicatat pada kecepatan $10 \mathrm{~km} / \mathrm{jam}$ sampai $70 \mathrm{~km} / \mathrm{jam}$ dan sisa kapasitas 0\%, 25\%, 50\%, 75\% dan 100\%. Data rata-rata hasil percobaan tercatat pada tabel 3.4 dan 3.5

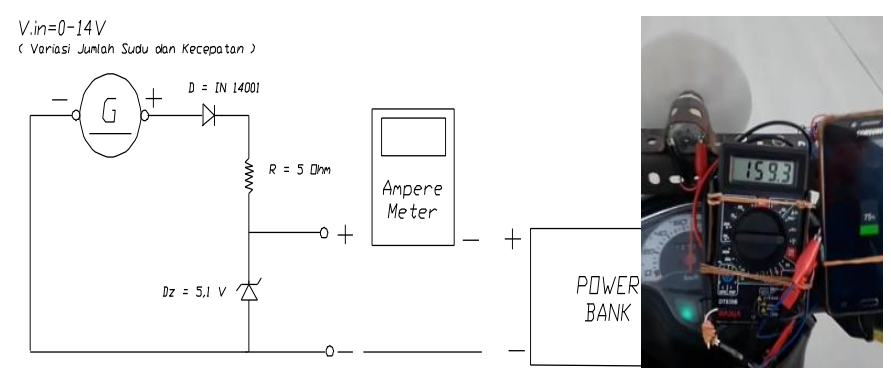

Gambar 2.6 Skema dan Foto percobaan 3

\section{HASIL DAN PEMBAHASAN}

\subsection{Percobaan 1}

Berikut ini adalah Tabel Tegangan rata-rata dan Kecepatan rotasi permenit rata-rata yaitu pada tabel 3.1 dan tabel 3.2

Tabel 3.1 Variasi Kecepatan dengan Jumlah sudu terhadap Tegangan rata-rata

\begin{tabular}{|c|r|r|r|r|r|r|r|l|}
\hline \multirow{2}{*}{$\begin{array}{c}\text { JUMLAH } \\
\text { SUDU }\end{array}$} & \multicolumn{6}{|c|}{ KECEPATAN BERKENDARA ( Km/Jam ) } & \multirow{2}{*}{ KETERANGAN } \\
\cline { 2 - 8 } & $\mathbf{1 0}$ & $\mathbf{2 0}$ & $\mathbf{3 0}$ & $\mathbf{4 0}$ & $\mathbf{5 0}$ & $\mathbf{6 0}$ & $\mathbf{7 0}$ & \\
\hline $\mathbf{2}$ & 0 & 0 & 0 & 0.00 & 0.42 & 4.22 & 11.02 & Volt \\
\hline $\mathbf{3}$ & 0 & 0 & 0 & 0.00 & 0.54 & 4.40 & 10.56 & Volt \\
\hline $\mathbf{4}$ & 0 & 0 & 0 & 0.74 & 2.44 & 7.14 & 11.70 & Volt \\
\hline $\mathbf{5}$ & 0 & 0 & 0 & 0.82 & 3.10 & 6.90 & 10.84 & Volt \\
\hline $\mathbf{6}$ & 0 & 0 & 0 & 1.18 & 5.26 & 8.32 & 10.06 & Volt \\
\hline
\end{tabular}

Tabel 3.2 Variasi Kecepatan dengan jumlah sudu terhadap rpm rata-rata

\begin{tabular}{|c|r|r|r|r|r|r|r|l|}
\hline \multirow{2}{*}{$\begin{array}{c}\text { JUMLAH } \\
\text { SUDU }\end{array}$} & \multicolumn{6}{|c|}{ KECEPATAN BERKENDARA ( Km/Jam ) } & \multirow{2}{*}{ KETERANGAN } \\
\cline { 2 - 8 } & $\mathbf{1 0}$ & $\mathbf{2 0}$ & $\mathbf{3 0}$ & $\mathbf{4 0}$ & $\mathbf{5 0}$ & $\mathbf{6 0}$ & $\mathbf{7 0}$ & \\
\hline $\mathbf{2}$ & 0 & 0 & 0 & 0 & 504 & 1477 & 3059 & $\mathrm{rpm}$ \\
\hline $\mathbf{3}$ & 0 & 0 & 0 & 0 & 572 & 1761 & 2908 & $\mathrm{rpm}$ \\
\hline $\mathbf{4}$ & 0 & 0 & 0 & 581 & 1257 & 2708 & 3216 & $\mathrm{rpm}$ \\
\hline $\mathbf{5}$ & 0 & 0 & 0 & 541 & 1189 & 2276 & 3015 & $\mathrm{rpm}$ \\
\hline $\mathbf{6}$ & 0 & 0 & 0 & 740 & 1588 & 2225 & 2845 & $\mathrm{rpm}$ \\
\hline
\end{tabular}

Dari percoban yang dilakukan Tegangan mulai muncul saat kecepatan $40 \mathrm{~km} /$ jam untuk Sudu 4,5 dan 6. Tetapi pada sudu 2 dan 3 tegangan mulai ada pada saat kecepatan $50 \mathrm{~km} / \mathrm{jam}$. Terjadi kenaikan nilai 
Tegangan saat kecepatan bertambah, pada kecepatan $70 \mathrm{~km} / \mathrm{jam}$ Tegangan pada sudu 2 lebih besar dari sudu 6. (Tabel 3.1).

Pada saat kecepatan rendah, sudu 6 lebih efektif dari pada sudu 2,3,4 dan 5 karena pada kecepatan 50 $\mathrm{km} / \mathrm{jam}$ sudah menghasilkan tegangan sebesar 5,26 volt yang sudah bisa digunakan untuk proses pengisian ke Power Bank. Tetapi pada kecepatan tinggi $(70 \mathrm{~km} / \mathrm{jam})$, kurang efektif karena tegangan yang dihasilkan masih dibawah sudu 3,4 dan 5. Sehingga sudu 4 lebih efektif, karena menghasilkan Tegangan sebesar 11,7 volt.

Kecepatan rotasi per menit, sebanding dengan kecepatan dan tegangan. Semakin tinggi kecepatan, maka Tegangan dan rpm yang dihasilkan oleh Generator DC juga akan semakin besar.

\subsection{Percobaan 2}

Berikut ini adalah Tabel Tegangan rata-rata setelah dipasang Rangkaian pembatas tegangan, pada Tabel 3.3

Tabel 3.3 Variasi kecepatan dengan jumlah sudu terhadap Tegangan rata-rata

\begin{tabular}{|c|r|r|r|r|r|r|r|l|}
\hline \multirow{2}{*}{$\begin{array}{c}\text { JUMLAH } \\
\text { SUDU }\end{array}$} & \multicolumn{6}{|c|}{ KECEPATAN BERKENDARA ( Km/Jam ) } & \multirow{2}{*}{ KETERANGAN } \\
\cline { 2 - 8 } & $\mathbf{1 0}$ & $\mathbf{2 0}$ & $\mathbf{3 0}$ & $\mathbf{4 0}$ & $\mathbf{5 0}$ & $\mathbf{6 0}$ & $\mathbf{7 0}$ & \\
\hline $\mathbf{2}$ & 0 & 0 & 0.00 & 0.00 & 0.90 & 4.80 & 5.10 & Volt \\
\hline $\mathbf{3}$ & 0 & 0 & 0.00 & 0.02 & 1.80 & 5.06 & 5.16 & Volt \\
\hline $\mathbf{4}$ & 0 & 0 & 0.00 & 0.54 & 4.36 & 5.10 & 5.20 & Volt \\
\hline $\mathbf{5}$ & 0 & 0 & 0.02 & 1.10 & 4.68 & 5.08 & 5.20 & Volt \\
\hline $\mathbf{6}$ & 0 & 0 & 0.04 & 1.80 & 4.92 & 5.10 & 5.20 & Volt \\
\hline
\end{tabular}

Dari percoban yang dilakukan dengan menambah Dioda Zener dan Resistor (Rangkaian pembatas tegangan) terdapat pengaruh terhadap Tegangan yang dihasilkan, karena pada kecepatan 70 $\mathrm{km} /$ jam nilai Tegangannya masih dalam batas toleransi yaitu sebesar 5,2 volt. Untuk tegangan pada sudu 4,5 dan 6 lebih efektif dari pada sudu 2 dan 3, karena pada kecepatan $50 \mathrm{~km} / \mathrm{jam}$ sudah memenuhi batas minimal Tegangan untuk pengisian arus ke Power bank.

Diode zener 5,1 volt (Rangkaian pembatas tegangan) bekerja efektif terhadap kestabilan Tegangan yang dihasilkan dari Generator Listrik DC pada kecepatan $60 \mathrm{~km} / \mathrm{jam}$ dan $70 \mathrm{~km} / \mathrm{jam}$ dengan nilai Tegangan Maksimal sebesar 5,2 volt.

\subsection{Percobaan 3}

Berikut ini adalah Tabel Arus rata-rata setelah dipasang rangkaian pembatas tegangan, pada saat kapasitas Power Bank 100\% sampai 0\%. Pada Tabel 3.4 dan Tabel 3.5

Tabel 3.4 Variasi Kecepatan dengan jumlah sudu terhadap Arus rata-rata yang dihasilkan (100\%-25\%)

\begin{tabular}{|c|r|r|r|r|r|r|r|l|}
\hline \multirow{2}{*}{$\begin{array}{c}\text { JUMLAH } \\
\text { SUDU }\end{array}$} & \multicolumn{6}{|c|}{ KECEPATAN BERKENDARA ( Km/Jam ) } & \multirow{2}{*}{ KETERANGAN } \\
\cline { 2 - 7 } & $\mathbf{1 0}$ & $\mathbf{2 0}$ & $\mathbf{3 0}$ & $\mathbf{4 0}$ & $\mathbf{5 0}$ & $\mathbf{6 0}$ & $\mathbf{7 0}$ & \\
\hline $\mathbf{2}$ & 0 & 0 & 0 & 0.00 & 0.74 & 21.13 & 98.93 & $\mathrm{~mA}$ \\
\hline $\mathbf{3}$ & 0 & 0 & 0 & 0.00 & 7.21 & 41.56 & 108.13 & $\mathrm{~mA}$ \\
\hline $\mathbf{4}$ & 0 & 0 & 0 & 0.08 & 18.52 & 102.43 & 162.39 & $\mathrm{~mA}$ \\
\hline $\mathbf{5}$ & 0 & 0 & 0 & 0.09 & 16.11 & 92.53 & 151.13 & $\mathrm{~mA}$ \\
\hline $\mathbf{6}$ & 0 & 0 & 0 & 0.13 & 17.68 & 93.68 & 147.13 & $\mathrm{~mA}$ \\
\hline
\end{tabular}

Tabel 3.5 Variasi kecepatan dengan jumlah sudu terhadap Arus rata-rata yang dihasilkan $(0 \%)$

\begin{tabular}{|c|r|r|r|r|r|r|r|l|}
\hline \multirow{2}{*}{$\begin{array}{c}\text { JUMLAH } \\
\text { SUDU }\end{array}$} & \multicolumn{6}{|c|}{ KECEPATAN BERKENDARA ( Km/Jam ) } & \multirow{2}{*}{ KETERANGAN } \\
\cline { 2 - 7 } & $\mathbf{1 0}$ & $\mathbf{2 0}$ & $\mathbf{3 0}$ & $\mathbf{4 0}$ & $\mathbf{5 0}$ & $\mathbf{6 0}$ & $\mathbf{7 0}$ & \\
\hline $\mathbf{2}$ & 0 & 0 & 0 & 0.00 & 0.00 & 9.50 & 19.37 & $\mathrm{~mA}$ \\
\hline $\mathbf{3}$ & 0 & 0 & 0 & 0.00 & 0.47 & 20.60 & 11.70 & $\mathrm{~mA}$ \\
\hline $\mathbf{4}$ & 0 & 0 & 0 & 0.03 & 7.90 & 84.53 & 15.70 & $\mathrm{~mA}$ \\
\hline $\mathbf{5}$ & 0 & 0 & 0 & 0.03 & 5.90 & 43.27 & 13.77 & $\mathrm{~mA}$ \\
\hline $\mathbf{6}$ & 0 & 0 & 0 & 0.00 & 5.30 & 61.77 & 23.07 & $\mathrm{~mA}$ \\
\hline
\end{tabular}

Dari percoban yang dilakukan Terjadi perbedaan besar Arus yang mengalir jika kapasitas energi dalam power bank berbeda, pengisian Arus terbesar terjadi pada kapasitas energi Power bank sebesar 25\% (sisa energi sebesar $650 \mathrm{mAh}$ ) dan sudu 4 paling efektif dibandingkan dengan sudu 2,3,5 dan 6. Karena menghasilkan Arus rata-rata terbesar yaitu 162,39 mA pada kecepatan $70 \mathrm{~km} / \mathrm{jam}$ (Tabel 3.4)

Baling - baling dengan jumlah sudu 4, menghasilkan arus terbesar pada saat sisa kapasitas Power Bank 100\% sampai 25\%. Proses pengisian arus tidak stabil, saat kapasitas energi Power Bank sebesar $0 \%$. Arus cenderung menurun pada semua sudu, tabel 3.5 sehingga perlu adanya penelitian lanjutan.

\subsection{Perhitungan Daya rata-rata.}

Mengacu pada Peraturan No.111 tahun 2015 tentang Kecepatan berkendara, Pada Pasal 3 point 4.C, maka untuk pengukuran Daya rata-rata dilakukan mulai kecepatan $50 \mathrm{~km} / \mathrm{jam}$ sampai $70 \mathrm{~km} / \mathrm{jam}$. Karena pada kecepatan $40 \mathrm{~km} / \mathrm{jam}$ kebawah Daya yang dihasilkan terlalu kecil.

Daya (P) adalah besarnya Tegangan (V) dikalikan dengan besarnya Arus (I) yang mengalir, sehingga dirumuskan :

$$
\mathrm{P}=\mathrm{V} \cdot \mathrm{I}
$$

Dari Tegangan rata-rata yang dihasilkan oleh Rangkaian pembatas Tegangan (tabel 3.3) dan Arus listrik rata-rata saat pengisian pada Power Bank (Tabel 3.4) maka didapatkan Daya rata-rata pengisian secara teoritis, seperti pada tabel 3.6 sebagai berikut:

Tabel 3.6 Daya rata-rata yang dihasilkan pada saat kapasitas Power Bank 100\% sampai 25\%

\begin{tabular}{|c|r|r|r|r|r|r|r|l|}
\hline \multirow{2}{*}{$\begin{array}{c}\text { JUMLAH } \\
\text { SUDU }\end{array}$} & \multicolumn{6}{|c|}{ KECEPATAN BERKENDARA ( Km/Jam ) } & \multirow{2}{*}{ KETERANGAN } \\
\cline { 2 - 8 } & $\mathbf{1 0}$ & $\mathbf{2 0}$ & $\mathbf{3 0}$ & $\mathbf{4 0}$ & $\mathbf{5 0}$ & $\mathbf{6 0}$ & $\mathbf{7 0}$ & \\
\hline $\mathbf{2}$ & 0 & 0 & 0 & 0.00 & 0.67 & 101.44 & 504.56 & $\mathrm{~mW}$ \\
\hline $\mathbf{3}$ & 0 & 0 & 0 & 0.00 & 12.98 & 210.29 & 557.97 & $\mathrm{~mW}$ \\
\hline $\mathbf{4}$ & 0 & 0 & 0 & 0.05 & 80.73 & 522.37 & 844.44 & $\mathrm{~mW}$ \\
\hline $\mathbf{5}$ & 0 & 0 & 0 & 0.10 & 75.39 & 470.03 & 785.89 & $\mathrm{~mW}$ \\
\hline $\mathbf{6}$ & 0 & 0 & 0 & 0.23 & 87.00 & 477.79 & 765.05 & $\mathrm{~mW}$ \\
\hline
\end{tabular}




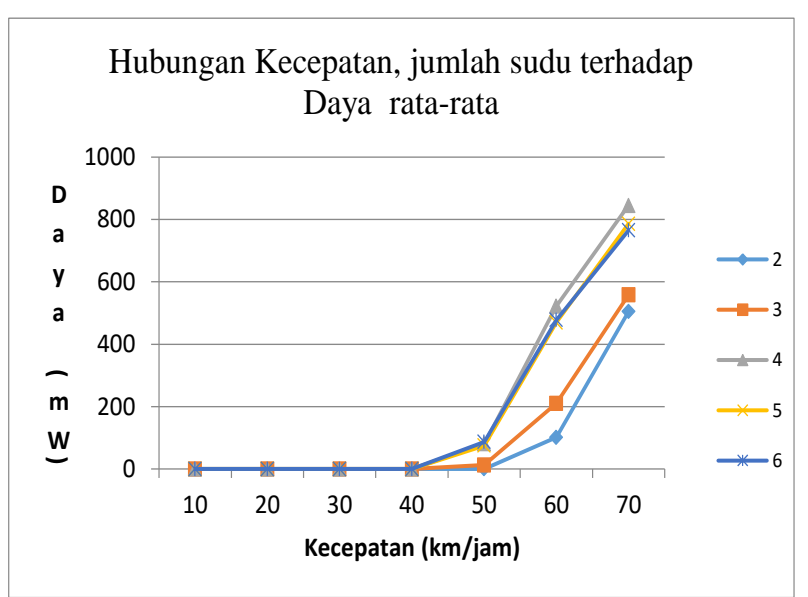

Gambar 3.1 Grafik Daya rata-rata yang dihasilkan pada saat kapasitas Power Bank 100\% sampai 25\%

Keterangan :

A. Pada Sudu 2
a) $P=$ V.I $(0,9$ v. $0,74 \mathrm{~mA})$ $\mathrm{km} / \mathrm{jam}$.
b) $\mathrm{P}=\mathrm{V} . \mathrm{I}(4,8$ v. $21,13 \mathrm{~mA})$ $60 \mathrm{~km} / \mathrm{jam}$
c) $P=$ V.I $(5,1$ v. $98,93 \mathrm{~mA}) \quad=504,56 \mathrm{~mW}$ saat $70 \mathrm{~km} / \mathrm{jam}$

B. Pada Sudu 3
a) $P=$ V.I $(1,8$ v. $7,21 \mathrm{~mA})$ $50 \mathrm{~km} / \mathrm{jam}$
b) $P=$ V.I $(5,06$ v. $41,56 \mathrm{~mA})=210,29 \mathrm{~mW}$ saat $60 \mathrm{~km} / \mathrm{jam}$
c) $\mathrm{P}=$ V.I $(5,16$ v. $108,13 \mathrm{~mA})=557,97 \mathrm{~mW}$ saat $70 \mathrm{~km} / \mathrm{jam}$

C. Pada Sudu 4
a) $\mathrm{P}=$ V.I $(4,36$ v. $18,52 \mathrm{~mA})=80,73 \mathrm{~mW}$ saat $50 \mathrm{~km} / \mathrm{jam}$.
b) $\mathrm{P}=\mathrm{V} . \mathrm{I}(5,1 \mathrm{v} \cdot 102,43 \mathrm{~mA})=522,37 \mathrm{~mW}$ saat $60 \mathrm{~km} / \mathrm{jam}$
c) $P=$ V.I $(5,2$ v. $162,39 \mathrm{~mA})=844,44 \mathrm{~mW}$ saat $70 \mathrm{~km} / \mathrm{jam}$

D. Pada Sudu 5
a) $\mathrm{P}=$ V.I $(4,68 \mathrm{v} \cdot 16,11 \mathrm{~mA})=75,39 \mathrm{~mW}$ saat $50 \mathrm{~km} / \mathrm{jam}$.
b) $P=$ V.I $(5,08 \mathrm{v} \cdot 151,13 \mathrm{~mA})=470,03 \mathrm{~mW}$ saat $60 \mathrm{~km} / \mathrm{jam}$
c) $\mathrm{P}=\mathrm{V} . \mathrm{I}(5,2$ volt. $84,5 \mathrm{~mA})=785,89 \mathrm{~mW}$ saat $70 \mathrm{~km} / \mathrm{jam}$

E. Pada Sudu 6
a) $\mathrm{P}=$ V.I $(4,92 \mathrm{v} \cdot 17,68 \mathrm{~mA}) \quad=87,0 \mathrm{~mW}$ saat 50 $\mathrm{km} / \mathrm{jam}$.
b) $\mathrm{P}=\mathrm{V} . \mathrm{I}(5,1 \mathrm{v} .93,68 \mathrm{~mA}) \quad=477,79 \mathrm{~mW}$ saat $60 \mathrm{~km} / \mathrm{jam}$
c) $\mathrm{P}=\mathrm{V} . \mathrm{I}(5,2$ v. $147,13 \mathrm{~mA})=765,05 \mathrm{~mW}$ saat $70 \mathrm{~km} / \mathrm{jam}$

Dari data perhitungan diatas, didapatkan kesimpulan : Daya pengisian yang dihasilkan oleh sudu 4 terbesar dibandingkan dengan sudu 2,3,5 dan 6. Jadi jumlah sudu paling efektif terhadap Daya yang dihasilkan oleh Generator listrik DC saat berkendara adalah sudu 4 sebesar 844,44 $\mathrm{mW}$ pada kecepatan 70 $\mathrm{km} / \mathrm{jam}$. Sedang pada kecepatan rendah $50 \mathrm{~km} / \mathrm{jam}$ baling-baling dengan jumlah sudu 6 paling efektif karena menghasilkan Daya terbesar $87 \mathrm{~mW}$.

\section{Teorema}

\section{Generator listrik DC}

Generator DC (Arus searah) adalah alat untuk mengubah Energi gerak/mekanis yang berupa putaran menjadi Energi listrik DC (Arus searah). Energi mekanik sudu akan memutar kumparan di dalamnya dan medan magnet akan timbul ggl. Hukum Faraday menyebutkan perubahan Garis Gaya Magnet pada kawat kumparan, akan menimbulkan gaya gerak listrik (ggl) di kumparan itu. Jika kawat kumparan tersebut dihubungkan rangkaian listrik yang tertutup, maka pada rangkaian tersebut akan terjadi Arus listrik. Perbedaan setiap Generator umumnya terletak pada komponen penyearahnya yaitu komutator dan sikat.

Kaidah tangan kanan fleming merupakan sebuah metode mneumonik agar kita mudah untuk mencari arah vektor dari komponen hukum Faraday yang terdiri dari 3 komponen, yaitu arah gaya gerak kumparan yang ditunjukkan oleh ibu jari, arah medan magnet yang ditunjukkan oleh jari telunjuk dan arah Arus listrik yang ditunjukkan oleh jari tengah.

Generator listrik DC (Direct Current/Arus searah) terdiri dari rotor dan stator. Rotor Generator DC memiliki bentuk persegi panjang yang tersusun dari kumparan kawat angker yang menghantarkan listrik (armature) . Diujung - ujung nya terpasang sebuah komutator yang terbagi dua dan berbentuk lingkaran, komponen ini disebut cincin belah. Cincin belah merupakan bagian rotor, sehingga berputar bersama rotor. Sedang Stator pada Generator DC terdiri dari dua magnet yang kutubnya berbeda dan berhadapan. Bagian yang bersentuhan dengan cincin belah, pada stator terhubung dengan sikat karbon sehingga mengalirkan Arus listrik ke rangkaian luar Generator.

Pada umumnya Generator DC menggunakan lebih dari satu buah lilitan pada kumparan kawat angkernya. Karena dengan menggunakan jumlah lilitan yang banyak maka akan menghasilkan tegangan (voltase) yang semakin stabil per satuan waktu. Pada grafik tegangan (voltase) Celah pada tengah gelombang tegangan akan semakin rapat. Sehingga semakin banyak jumlah lilitannya, maka celah-celah tersebut akan semakin tertutup. sehingga grafik voltasenya akan semakin stabil dan rata. 


\section{Dioda Zener}

Dioda Zener merupakan Dioda yang karakteristiknya menyalurkan Arus listrik yang melewatinya ke arah berlawanan jika Tegangan input nya melebihi batas Tegangan Zener nya. Sedangkan dioda biasa hanya menyalurkan/ meneruskan Arus listrik ke satu arah saja.

Sedangkan Dioda biasa tidak akan bisa mengalirkan Arus listrik secara berlawanan jika dicatubalik (reverse-biased) dengan Tegangan masuknya di bawahnya. Dioda biasa akan rusak karena panas Jika tegangan masuk melampaui batas Tegangan operasionalnya akibat kelebihan Arus listrik.

Tegangan yang dihasilkan Dioda Zener besarnya akan sama/mendekati dengan nilai tegangan pada Diode Zener. sehingga Dioda Zener digunakan sebagai Pengatur Tegangan (Voltage Regulator). Karena Dioda Zener akan menghasilkan Tegangan sesuai besar nilai Tegangan Zenernya meskipun Tegangan (Voltase) Input yang diberikan diatas nilai zenernya.

Berikut adalah gambar skema dan foto Rangkaian pembatas tegangan yang digunakan dalam penelitian ini.
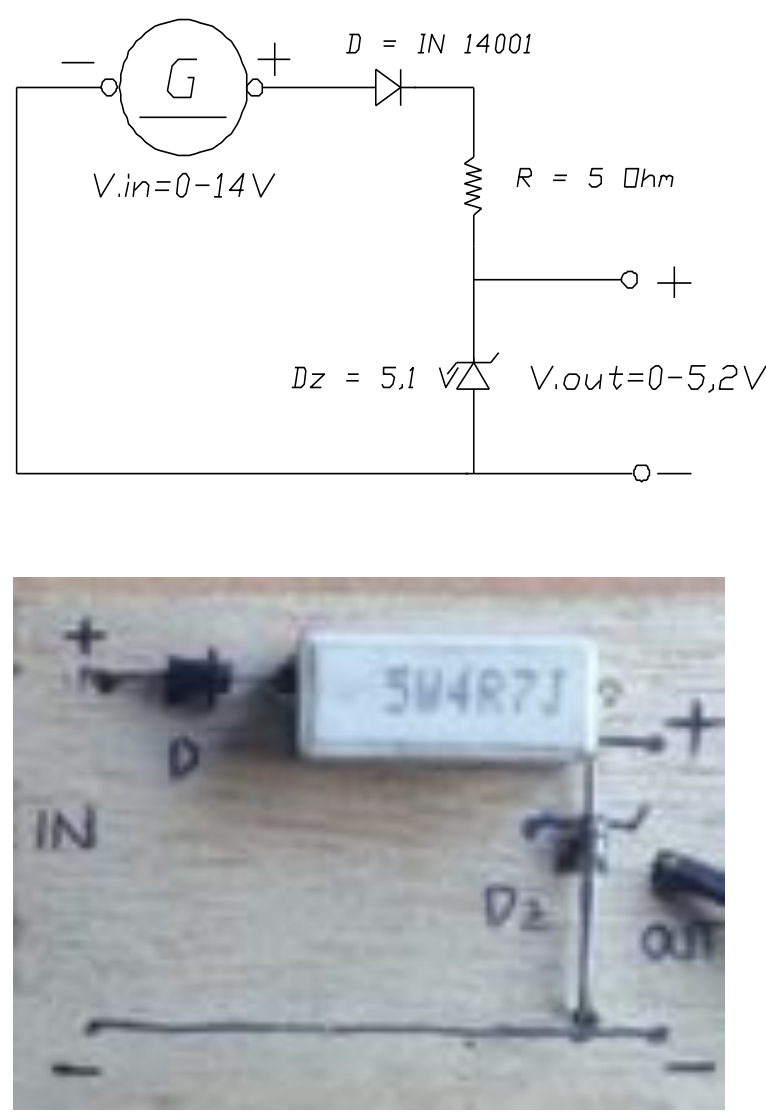

Gambar 3.2 Skema dan Foto Rangkaian pembatas tegangan
Keterangan :

D = Dioda biasa/ Dioda penyearah 1 A (IN 14001), digunakan untuk mencegah arus balik dari Power Bank ke Generator DC agar baling-baling sudu tidak bergerak (berputar) saat tidak berkendara (kecepatan $0 \mathrm{~km} / \mathrm{jam}$ ) sehingga tidak menyebabkan isi kapasitas Power Bank berkurang.

$\mathrm{R}=$ Resistor Keramik 5 $\Omega / 5$ Watt, digunakan untuk membatasi Arus listrik yang mengalir. Semakin besar nilai Resistor maka Arus pengisian ke Power Bank akan semakin kecil, daya yang dipakai 5 watt untuk mencegah kerusakan pada Resistor akibat panas saat arus yang mengalir besar.

$\mathrm{Dz}$ = Dioda Zener 5,1v/1 Watt, digunakan untuk membatasi besarnya tegangan yang hasilkan sebesar 5,1 volt. Daya 1 watt untuk faktor keamanan, karena daya saat pengisian pada penelitian ini masih dibawah 1 watt.

\section{PENUTUP}

Dari penelitian yang dilaksanakan pengaruh Jumlah sudu terhadap daya yang dihasilkan generator listrik DC saat berkendara, didapatkan kesimpulan bahwa:

Sudu dengan jumlah banyak (sudu 6), efektif dalam menghasilkan tegangan pada kecepatan rendah ( $50 \mathrm{~km} / \mathrm{jam}$ ) sebesar 5,26 volt pada tabel 4.6 tetapi pada kecepatan tinggi (70km/jam) jumlah sudu 4 lebih efekti karena dapat menghasilkan tegangan tinggi sebesar 11,70 volt pada tabel 3.2

Dioda Zener (Rangkaian pembatas tegangan) efektif dalam membatasi variasi tegangan masuk, dengan nilai Tegangan maksimal 5,2 volt pada kecepatan $70 \mathrm{~km} / \mathrm{jam}$. Pada tabel 3.3

Proses pengisian Arus pada Power Bank dengan sisa kapasitas sedikit (25\%) lebih besar dari pada saat kapasitas Power Bank penuh (100\%). Tetapi pada saat kapasitas Power Bank kosong (0 \%) pengisian arus cenderung kecil dan tidak Stabil. Pada tabel 3.4 dan 3.5

Baling - baling dengan jumlah sudu 4 menghasilkan Arus rata-rata terbesar dibandingkan sudu 2,3,5 dan 6. Sehingga Daya terbesar dihasilkan baling-baling dengan jumlah sudu 4 pada kecepatan $70 \mathrm{~km} / \mathrm{jam}$, sebesar 844,44 mW. Maka sudu 4 paling efektif untuk menghasilkan daya maksimal saat berkendara. Pada tabel 3.6

Dalam pengerjaan Penelitian ini kami yakin masih banyak kekurangan sehingga perlu adanya penelitian lanjutan untuk lebih memaksimalkan daya yang diperoleh. Beberapa saran yang perlu diperhatikan untuk dapat mencapai hasil yang lebih baik antara lain :

Pengaruh akurasi desain sudu, baik bentuk luasan maupun sudut kemiringan sudu terhadap tegangan dan rpm yang dihasilkan. 
Penambahan rangkaian penstabil arus, sehingga walaupun kapasitas Power Bank 0\% Arus yang mengalir bertambah besar dan tetap stabil. Jadi pengisian Arus bisa dilakukan pada saat kapasitas Power Bank Kosong (0\%) sampai penuh (100\%).

\section{UCAPAN TERIMA KASIH}

Ucapan terima kasih kepada seluruh Dosen Umaha, Khususnya Dosen Teknik Mesin (Bapak Ir. Subagyo MT) atas bimbingan dan saran diberikan sehingga Saya dapat menyelesaikan penelitian ini tepat waktu. Serta teman - teman dan keluarga atas dukungannya.

\section{DAFTAR PUSTAKA}

Adriani, A. (2018). Perancangan Pembangkit Listrik Kincir Angin menggunakan Generator Dinamo Drillini terhadap Empat Sumbu Horizontal. Jurnal INSTEK (Informatika Sains Dan Teknologi), 3(1), 71-80 https://doi.org/10.24252/instek.v3i1.4821

Enny, E. (2019). Tachometer Laser , Pemakaian Dan Perawatannya. METANA, 13(1), 7. https://doi.org/10.14710/metana.v13i1.125 78

F. Anggraini, A. Surtono, G. P. (2016). Pemanfaatan Energi Angin pada Sepeda Motor Bergerak untuk Menyalakan Lampu. Jurnal Teori Dan Aplikasi, 4(2), 167-174.

KEMENHUB. (2015). PM_111_Tahun_2015.pdf. Retrieved from http://jdih.dephub.go.id/assets/uudocs/per men/2015/PM_111_Tahun_2015.pdf

Mereness, T. S. (1975). Bicycle tachometer/speedometer. IBM Technical Disclosure Bulletin, 17(9), 2570-2571.

Nuarsa, M., Teknik, J., Fakultas, M., \& Universitas, T. (2013). TERHADAP UNJUK KERJA TURBIN ANGIN POROS HORIZONTAL. 3(1), 50-59.

Rahmat Nanang, Gunarto1), E. sarwono2). (2017). Study Eksperimental Berbagai Macam Jenis Sudu Turbin Angin Sumbu Horisontal Skala Laboratorium. 3(2), 113-120. https://doi.org/10.1002/14356007.a25

Ratings, A. M. (n.d.). Zener Diode Zener Diode. 1-5.

Ridwanto, A., \& Broto, W. (2017). Perancangan power bank dengan menggunakan dinamo sepeda sederhana. Prosiding Seminan Nasional Fisika (E-Journal) SNF2017, 6, 4956. https://doi.org/https://doi.org/10.21009/0 3.SNF2017

Saputra, W. N., Despa, D., Soedjarwanto, N., Samosir, A. S., Teknik, J., Universitas, E., ... Uno, A. (2016). Prototype Generator DC Dengan Penggerak. 4(1). Retrieved from http://journal.eng.unila.ac.id/index.php/jitet /article/view/538/589

Soleh, R. M., Rizal, A., Elektro, T., Kedokteran, R. P., Simpliscribe, C., Ecg, B., ... Kerja, C. (2018). Elektronika Dasar. Http://ElektronikaDasar.Web.Id/Penguat-Tak-Membalik-NonInverting-Amplifier/.

Sulhi, M. S., Ningrum, T. C., Sari, Y., Studi, P., \& Informatika, T. (n.d.). Tangga Sebagai Pembuatan Powerbank Pintar. 273-277. 
Rudianto / Mechonversio, Vol. 2, No.2, Desember 2019, 43-56

Halaman ini sengaja dikosongkan 